\title{
Strategic Planning and Staff Management as Determinants of Post-Graduate Programmes' Effectiveness in Universities
}

\section{Running Head: Strategic Planning and Staff Management in PGPE}

\author{
Mary Mark Ogbeche $^{1 \mathrm{i}}$, Kelechi Victoria Emeribe ${ }^{1 \mathrm{ii}}$, Stella Asu-Okang ${ }^{1 \mathrm{iii},}$ Caroline Ephraim Etim $^{1 \mathrm{iv}}$, \\ Valentine Joseph Owan,"*v
}

${ }^{1}$ Department of Educational Management, University of Calabar, Calabar-Nigeria

${ }^{2}$ Department of Educational Foundations, University of Calabar, Calabar-Nigeria

Received September 27, 2021; Revised November 12, 2021; Accepted November 29, 2021

\section{Cite This Paper in the following Citation Styles}

(a): [1] Mary Mark Ogbeche1, Kelechi Victoria Emeribe, Stella Asu-Okang, Caroline Ephraim Etim, Valentine Joseph Owan, "Strategic Planning and Staff Management as Determinants of Post-Graduate Programmes' Effectiveness in Universities," Universal Journal of Educational Research, Vol. 9, No. 12, pp. 1962 - 1970, 2021. DOI: 10.13189/ujer.2021.091208.

(b): Mary Mark Ogbeche1, Kelechi Victoria Emeribe, Stella Asu-Okang, Caroline Ephraim Etim, Valentine Joseph Owan (2021). Strategic Planning and Staff Management as Determinants of Post-Graduate Programmes' Effectiveness in Universities. Universal Journal of Educational Research, 9(12), 1962 - 1970. DOI: 10.13189/ujer.2021.091208.

Copyright $\bigcirc 2021$ by authors, all rights reserved. Authors agree that this article remains permanently open access under the terms of the Creative Commons Attribution License 4.0 International License

\begin{abstract}
This study linked strategic planning and staff management relatively and cumulatively to the effectiveness of post-graduate programmes at two public Nigerian universities. The study was directed by the formulation and testing of three null hypotheses. The entire population of 157 administrators (including 24 deans and 133 HODs) participated in a survey, where a questionnaire was used to elicit responses. The questionnaire was designed by the researcher but validated by five experts. The reliability for internal consistency was determined using Cronbach's alpha, with acceptable indices. Data obtained were analysed using Pearson correlation and multiple linear regression analyses. In a bivariate sense, both strategic planning and staff management significantly correlated with the effectiveness of post-graduate programmes respectively. Cumulatively, the two predictors are responsible for explaining $57 \%$ of the variation in the effectiveness of post-graduate programmes, with the remaining $43 \%$ of the unexplained variance attributable to other extraneous variables. The composite contribution of the two predictors was verified to be
\end{abstract}

statistically significant. Staff management was the strongest predictor ahead of strategic planning. It was recommended, among other things, that the coordinator of post-graduate programmes should ensure that plans are made concerning the procurement and maintenance of facilities that will be required for the smooth running of the programmes in graduate schools.

Keywords Effectiveness, Planning, Post-Graduate Programmes, Staff Management, Strategic Planning

\section{Introduction}

Post-graduate programmes in universities are intended to offer a more career-specific knowledge to students for professional development. Post-graduate programmes should be tailored to the training of individuals and to inculcate good research skills for problem-solving [1]. It was expected that such programmes will be managed 
effectively following global best practices. This should drive post-graduate programmes of universities towards efficiency, increased enrolment, competitiveness and subsequently, effectiveness [2-3]. However, within the universities in Cross River State, post-graduate programmes seem not to be adequately funded; learning plans are not also fully implemented and evaluated. It has also been documented that physical facilities are inadequate [4] to ensure the smooth running of post-graduate programmes. One serious evidence of this underfunding is the poor state of lecture venues with inadequate facilities such as lighting, ventilation, instructional materials, learning resources, and so on [5]. The available ones appear to be in a deplorable state without proper maintenance. Consequently, it is not uncommon to see graduate students learn under tree shades, open spaces, and public places, lecturers' offices, car parks, and pavilions as opposed to a comfortable environment that will promote effective learning and research [1].

Universities in Cross River State tend to adopt strategic planning, which involves outlining the vision, mission, core value, and its functions of educational programmes clearly [6-8] but the attainment of these plans are rarely achieved [1]. In another regard, staff appear to be mismanaged through delayed promotion, inconsistent payment of salaries, and poor provisions of educational support like grants to conduct researches, and other fringe benefits [9-12]. In today's world where information and communication technology are widely used, it is also disheartening to observe that ICT gadgets are inadequate and cannot match the number of students enrolled [1]. Consequently, records tend to be managed using obsolete approaches that seems to pose threats and makes it uneasy to retrieve such data. This seems to be in the opposite of computerized approaches that offer a higher level of reliability in the management of students' information. It is in the light of these issues that the present study has been designed to assess the extent to which strategic planning and staff management contribute respectively to the effectiveness of post-graduate programmes.

\section{Strategic Planning}

The word strategic planning refers to a collection of ideas, processes and instruments that are intended to help leaders and managers in the performance of their duties [13]. In addition, it provides an in-depth explanation of an organization's mission, objectives, and tactics. Strategic planning is receiving more and more prominence as a management strategy because of its ability to help educational institutions expand and become more successful [1]. The cited scholars added that it has the potential to serve as an important framework for the success of post-graduate programmes. This implies that school leaders must restructure their organizations to keep up with the many changes and unstable educational environment.
In Kenya, it was discovered that a variety of factors, including leadership styles, financial resources and training influence how strategic planning was carried out [14]. This suggests that strategic planning can only be implemented successfully if the right leadership is in place. The educational system in the nation should take a more creative and inventive approach to strategic planning, according to the recommendations given. According to the findings of Abdulkareem [15], the degree of execution of the strategic plan in Nigerian universities was poor compared to other countries. As a result, it was suggested that university management and faculty should be more committed to the implementation of an institutional strategic plan to attain internal efficacy. Researchers, Nwankwo et al. [16] discovered that university products end consumers needed to be included in strategic thinking and planning. To improve the quality of university administration, it was recommended that university management and employees get training and orientation on strategic thinking and that a strategic planning unit be created to facilitate this process.

The analysis conducted by Iso [17] on a sample of 273 administrators revealed that the strategic plan, database, information and communication technology resources, post-UTME screening test, university portal, and outsourced service all had a significant impact on the effectiveness of the university. According to the results, it was suggested, among other things, that university administration offer sufficient infrastructural facilities and instructional materials to create a conducive learning atmosphere that would encourage efficiency. Furthermore, Messah [18] examined the variables that influence how strategic administration plans for tertiary foundations are carried out in the Meru Central District of Kenya. Key evidence emerged that managerial behaviour had a limited impact because of the strategic thinking of the management team and institutional regulations. Lack of understanding, seldom adherence to a service charter, and a crucial indicator of strategy implementation efficiency, were also shown to be contributing factors.

In recent research, [1] determined that there is a major link between management practices and the sustainability of university graduate programs. The cited study also revealed that the efficacy of graduate courses in general, and in terms of finance and facility availability, as well as supervisory capacity are greatly influenced by certain management processes such as strategic planning, personnel management and IT management. Information and communication management was found to be the most important management process which influences the effectiveness of graduate programs.

\section{Staff Management}

The management of employees' skills, knowledge, competencies, abilities, talents, and attitudes to conform to 
school standards and to achieve educational goals refers to staff management [19]. Another definition was offered that staff personnel management as the acquisition, maintenance, and utilization of human resources to influence productivity, quality, and profitability in a bid to achieve the sustainable development of the educational system [20]. Effective management of staff (human resource) is geared towards the achievement of quality assurance, maintenance of standards and goal attainment for the effectiveness of the school system [1]. This means that the administrative wing of the university must engage in the strategic plan, provision of instructional facilities and generate an alternative source of funding for the effectiveness of post-graduate programmes.

According to the findings of Akeke and Ofem [23], there is a strong connection between staff training and quality assurance in a tertiary institution; there is also a significant relationship between the supply of incentives to employees and quality assurance in higher institutions. Based on the results, it was suggested that employees be encouraged and supported to attend conferences, seminars, workshops, and continue their studies to allow them to improve their expertise and get up-to-date information to guarantee quality. Moreover, Atanda [24] revealed among others, that there is no significant influence of recruitment, placement and motivation practices on the task performance of the staff of the ministry of education in Oyo state. The study concluded that the five personnel management practices are strong predictors in the performance of the staff of the Oyo state ministry of education.

Similarly, in another research, it was discovered that human resource management has a good and significant effect on employee' long-term productivity [25]. Because the success of any company is highly reliant on the efficient management of its human resources, the cited study is relevant to the current research. This suggests that leaders of universities must ensure quality assurance to produce quality graduates. This involves on-the-job training, monitoring and various incentives that motivate staff to be more productive [26].

In another study, it was discovered that teacher's job performance in the study region is significantly influenced by factors such as recruitment, promotion, and timely payment of wages [27]. Based on the results, it was suggested that the government hire competent and trained instructors and offer chances and incentives for employees to enhance skills and knowledge via workshops, seminars, and other training opportunities. The cited research is related to the current study because to achieve effective and efficient service delivery of staff personnel in the school system, adequate concentration is required through staff management.

Edet et al. [28] discovered that instructors' work performance significantly correlated with their use of conflict resolution methods in the classroom, including classroom management, upholding classroom discipline, and supervising students' academic activities. It has also been discovered that democratic, autocratic, and laissez-faire leadership styles all worked together to explain about 68.3 per cent of the variance in teachers' job performance [29]

Generally, all the studies cited herein, have used different methodologies that suit the unique purpose of each study. The findings from the studies cited in this study have arrived at various conclusions. While it seems that much has previously been done, there are still many gaps in the literature that the current research filled. Some of the studies that are cited were performed in other nations, and there is relatively little research that has been carried out in Nigeria on the subject matter.

This study is of immense value to lecturers, departmental heads, deans, universities administrators, regulatory bodies, policymakers, educational researchers and other educational stakeholders. The study may enable lecturers to measure up their performance of ensuring effectiveness. Using the results from this research, department heads will be able to see for themselves whether or not their organizations are doing a good job in managing post-graduate programmes effectively. This study will also give feedback to enable administrators in readjusting and correcting their management deficiencies and reorient their management approaches for effectiveness. It will guide regulatory bodies and the government on areas where they could pay more attention to promote effectiveness. It could also be an indispensable material to all those genuinely interested in quality and functional educational research in Nigeria and beyond.

\section{Statement of Problem}

In recent years, educational stakeholders in Cross River State and Nigeria have been more concerned about the long-term viability of graduate programs. Universities that are supposed to be the most prestigious institutions are gradually decreasing in quality and the quality of their products. Graduates from most institutions often tend to seek postgraduate admission at colleges elsewhere in the world in search of better opportunities. The migration in search of greener pastures tends to affect the number of students available for universities in the State to enrol. This appears to affect the sustainability of postgraduate programmes because no programme can continue to operate with little or no enrolment.

Furthermore, most postgraduate students seem to lack effective abilities in learning and research that were intended to be developed in graduate programs. For lecturers in institutions, the use of computers and other advanced ICT devices in engaging students and doing research was also expected to be necessary for the 21st century. But sadly, this does not seem to be the situation in Cross River State, where many graduate school instructors are not observed using such technologies to educate and 
supervise graduate students' investigations.

There is also a perceived danger that the outputs of graduate programs may not only be worthless, but they may also be ill-equipped to compete with their counterparts in other countries. As a result, despite the government's intervention on the funding of tertiary institutions, through channels such as the Tertiary Education Trust Fund (TETFUND) or the Education Trust Fund (ETF), these problems persist. This has prompted the researchers to ponder whether poor strategic planning and staff management are not to blame for the perceived lack of effectiveness of graduate programmes to produce highly specialized manpower.

\section{Aims of the Study \\ This study seeks to determine: \\ 1. the partial contribution of strategic planning to the effectiveness of post-graduate programmes in universities; \\ 2. the partial contribution of staff management to the effectiveness of post-graduate programs in universities; \\ 3. the composite prediction of strategic planning and staff management on the effectiveness of graduate programmes in universities.}

\section{Methodology}

\section{Research Design}

The correlational research methodology was used for this study because it was meant to determine whether or not there is a connection between the variables under consideration. Based on correlation coefficients, correlational research designs are employed in the studies that seek to determine the degree to which changes in one or more variables coincide with variations in one or more factors. It focuses on establishing or clarifying connections between variables through the use of the correlation coefficient [30]. Because this research investigated strategic planning, staff management, and their connections to the effectiveness of post-graduate programmes in universities, this design was deemed to be the most suitable for this study.

\section{Participants of the Study}

The research included a total of 157 administrators (including 24 Deans and 133 Heads of Departments (HODs)) from two public institutions in Cross River State. Following the census method, these participants reflect exactly one hundred per cent of the study's population at the institutions under investigation. "In situations when the population to be researched is small or controllable in such a way that all of the components within it can be investigated in their entirety, the census method is employed" [31 p. 42].

\section{The Instrument for Data Collection}

Data were collected using a questionnaire prepared by the researchers, following a review of the literature. The questionnaire was entitled: "Strategic Planning, Staff Management and Post-graduate Programmes' Effectiveness Scale (SPSMPPES). The SPSMPPES was structured into two sections. Responses to Section A were used to determine the demographic characteristics of the respondents. Answers to Section B provided information on the effectiveness of post-graduate programs. All of the items in section B were placed on a Likert-type scale with four possible responses. Response options ranged from Strongly Agree to Strongly Disagree. The validity of the instrument was determined by three psychometric and two planning specialists from the University of Calabar. The experts evaluated the instrument for both face and content validity. Each of these academics separately provided their observations. The items that were deemed extraneous were removed. Those requiring revisions were modified, while those that were considered relevant were kept. The researchers were guided in the preparation of the final draft as a result of the suggestions. With the use of the Cronbach alpha reliability method, internal consistency of the instrument was determined. For strategic planning, staff management, and the effectiveness of post-graduate programs, the reliability analysis produced coefficients of $.79, .87$, and .89 , respectively, according to the results.

\section{Data Collection and Analysis}

In collecting data for the study, the researchers visited the universities with copies of the questionnaire. The researchers obtaining prior permission and consent to administer the questionnaire and participate from the school management and respondents. With the aid of five research assistants who were educated on the objectives and techniques of the study, copies of the instrument were successfully administered to the targeted audience. An explicit explanation was provided in the questionnaire regarding the filling of the instruments to avoid any problem that may arise from misunderstanding. Upon completion, completed copies of the questionnaire were retrieved after two days from the respondents. In preparing the data collected for statistical analysis, a coding schedule was designed. Items in Section B of the questionnaire were coded for each variable based on the responses pattern. The scoring was as follows: Strongly Agree (SA) $=4$ marks, agree (A) $=3$ marks, Disagree (D) $=2$ marks and Strongly Disagree $(\mathrm{SD})=1$ mark for all positively written questions. The researchers decided to reverse the points awarded for items that were deemed to be negative. Data collected for 
the study were analysed using correlation and regression analyses with the aid of SPSS version 26 .

\section{Results}

\section{Hypothesis 1}

No significant relationship exists between strategic planning and the effectiveness of post-graduate programmes in universities. Strategic planning is the independent variable in this hypothesis, and the effectiveness of post-graduate programs is the dependent variable. The data for this hypothesis are continuous and were gathered on an interval scale of measurement. Correlation analysis was performed to test the null hypothesis at the .05 alpha level of significance. The result in Table 1 shows that there is a statistically significant link between strategic planning and the effectiveness of post-graduate programs $(\mathrm{r}=.53, \mathrm{p}<.05)$. As a consequence, the null hypothesis was rejected, while the alternative hypothesis was confirmed, which states that strategic planning has a strong connection with the effectiveness of post-graduate programs in institutions.

Table 1. Correlation Results of Strategic Planning and the Effectiveness of Post-Graduate Programmes $(\mathrm{N}=157)$

\begin{tabular}{|c|c|c|c|c|}
\hline Variables & Mean & SD & Cal r & p-value \\
\hline Strategic planning & 12.63 & 3.23 & & \\
\hline $\begin{array}{c}\text { Effectiveness of } \\
\text { post-graduate programmes }\end{array}$ & 12.50 & 2.66 & & $.53^{* *}$ \\
\hline $\begin{array}{c}* * \text { Significant at the } .01 \text { alpha } \\
\text { level (two-tailed) }\end{array}$ & $\mathrm{df}=155$ & & & \\
\hline
\end{tabular}

\section{Hypothesis 2}

Staff management has no discernible relationship with the effectiveness of post-graduate programmes in universities. Staff management is the independent variable in this hypothesis, whereas the effectiveness of graduate programmes is the dependent variable. Data for this hypothesis were continuous and measured on an interval scale. This conforms to the conditions for using Pearson product-moment correlation to analyse the connection between the variables of interest. At the .05 level of significance, the null hypothesis was tested, and the findings are reported in Table 2. Table 2 indicate that a strong positive connection exists between staff management and the effectiveness of postgraduate programmes in universities $(\mathrm{r}=.712, \mathrm{p}<.05)$. There was a statistically meaningful basis to reject the null hypothesis and maintain the alternative hypothesis going by the available data.

Table 2. Correlation Result of Staff Management and the Effectiveness of Post-Graduate Programmes in Universities $(\mathrm{N}=157)$.

\begin{tabular}{|c|c|c|c|c|}
\hline Variables & Mean & SD & Cal r. & p-value \\
\hline Staff management & 14.03 & 3.25 & & \\
\hline $\begin{array}{c}\text { Effectiveness of } \\
\text { post-graduate programmes }\end{array}$ & 12.50 & 2.66 & & $.712^{* *}$ \\
\hline $\begin{array}{c}* * \text { Significant at the .01 } \\
\text { alpha level (two-tailed) }\end{array}$ & $\mathrm{df}=155$ & & & \\
\hline
\end{tabular}

\section{Hypothesis 3}

Strategic planning and staff management have no significant composite contribution to the effectiveness of post-graduate programmes in universities. Two predictor variables and one response variable are presented in this hypothesis which were all measured continuously. The statistical tool employed for data analysis is multiple linear regression analysis. Table 3 presents a summary of the findings from the statistical analysis. The result in Table 3 indicate that the two predictor variables have joint positive multiple correlations $(\mathrm{R}=.76)$ with the effectiveness of postgraduate programmes. The two predictors account for $57 \%$ of the total variation in the effectiveness of post-graduate programmes at the universities. Because of this, additional independent variables not included in the model may be responsible for the remaining $43 \%$ of the unexplained variation in the dependent variable.

As can be seen in Table 3, the p-value of .00 falls below the .05 criterion of significance at 2 and 154 degrees of freedom. Strategic planning and staff management, therefore, have a substantial joint contribution on the effectiveness of post-graduate programmes at universities $(\mathrm{F}=98.25, \mathrm{p}<.05)$ based on the evidence gathered and presented. This means that the Adjusted R2 value of .57 was not a coincidence, which was previously reported. A closer look at the relative statistics in Table 3 showed that strategic planning $(\mathrm{t}=1.87, \mathrm{p}<.05)$ and staff management $(t=10.02, p<.05)$, are significant predictors of the effectiveness of post-graduate programmes in universities. Among these predictors, staff management was the strongest $(\beta=.68)$ trailed by strategic planning $(\beta=.13)$. The result also suggests that a $1 \%$ increase in strategic planning and staff management, will lead to a $0.13 \%$ and $0.68 \%$ change in the effectiveness of post-graduate programmes in universities, other things being equal. 
Table 3. Joint Contribution of Strategic Planning and Staff Management to the Effectiveness of Post-Graduate Programmes in Universities (N=157)

\begin{tabular}{|c|c|c|c|c|c|c|}
\hline $\mathrm{R}$ & $\mathrm{R}^{2}$. & Adj. $R^{2}$ & SE & & & \\
\hline .76 & .57 & .57 & 3.76 & & & \\
\hline Model & SS & $\mathrm{df}$ & MS & $\mathrm{F}$ & $\mathrm{p}$-value & \\
\hline Regression & 2770.42 & 2 & 1385.21 & 98.25 & .00 & \\
\hline Residual & 2058.34 & 154 & 14.10 & & & \\
\hline Total & 4828.77 & 156 & & & & \\
\hline Variables & B & SE & $\beta$ & $\mathrm{t}$ & p-value & Rank \\
\hline (Constant) & 1.98 & .99 & & 2.00 & .01 & \\
\hline Strategic planning & 0.13 & .07 & .13 & 1.87 & .00 & $2 \mathrm{nd}$ \\
\hline Staff management & 0.71 & .07 & .68 & 10.02 & .00 & $1 \mathrm{st}$ \\
\hline
\end{tabular}

\section{Discussion}

Strategic planning was shown to have a substantial impact on the effectiveness of post-graduate programmes in this research. This discovery does not come as a surprise because strategic plans are created to match an institution's demands, strengthen and enhance the institution's performance and quality. As a result, all required steps must be taken to ensure the proper operation of post-graduate programmes' activities. This includes plans in terms of budget preparation, source of funds, taking records of worn-out facilities and making procurement for their replacement. If all these plans are adequately implemented and funds become available, facilities will be provided where they were missing with worn-out facilities removed from the system [1]. Since plans on how to manage all the prospective resources have been earlier made, it goes a long way also strengthen the supervisory activities of the given room for the smooth running of the post-graduate programmes.

This finding is in tandem with the result of Iso [17] that there is a significant influence of strategic plan, database, information and communication technology resources, post-UTME screening test, university portal and outsourced service on the effectiveness of university and it is recommended amongst others that university management should provide adequate infrastructural facilities and instructional materials to promote a conducive learning environment which will foster effectiveness. Although the study of Iso [17] did not focus specifically on the effectiveness of post-graduate programmes, the implication of the finding is highly important to the present study which complements the generality of Iso's [17] finding. Nwankwo et al. [16] revealed that to improve the quality of university administration, the end-users of university goods should be included in strategic planning, with the proposal that university management and employees be given training and orientation on strategic thinking. Graduate programs will be able to move up the effectiveness ladder as a result of better-prepared university administrators making critical choices.

The second outcome of this research demonstrated a substantial link between staff management and the effectiveness of post-graduate programmes in institutions. The position of this finding is quite glaring due to the dynamic role staff plays generally in any school programme. In fact, without staff, post-graduate programmes will not only be non-effective but there will also be no post-graduate programmes at all. Although the mere presence of staff is not enough to make post-graduate programmes effective, they must be properly placed, assigned tasks, guided accordingly, given the appropriate working conditions, motivated, supervised strictly and evaluated consistently to ensure they work in line with goals and objectives of the programmes [21-22]. All these series of activities are what constitute staff management, and proper/consistent delivery of such administrative duties will promote the effective prospect of post-graduate programmes in Cross River State and beyond.

This result is consistent with the findings of Akeke and Ofem [23], who found that quality assurance in a tertiary institution is linked to staff training, as well as with the supply of incentives to employees. The study of Akeke and Ofem [23] was considered as being related to this study because the effectiveness of any graduate programme can be guaranteed when there is quality assurance in the university system. Therefore, if staff management (which includes training) is in place, quality will be assured, and the chances of reaching the heights of effectiveness will increase. The findings of this research also support the findings of Nyameh et al. [25], who discovered that human resource management has a favourable and substantial effect on long-term employee productivity. In separate 
research, it was discovered that teacher's job performance in the study region is significantly influenced by factors such as recruiting, promotion, and timely payment of wages, among other factors [25]. On the contrary, it was found that there is no significant relationship between the recruitment and placement practices of the ministry of education and the task performance of its employees [24]. The discrepancy in the findings is quite apparent, which may be attributed to differences in the research locations, the character of the respondents, and the period in which the investigations were conducted, amongst other factors. It is also clear that this study focus on the effectiveness of post-graduate programmes rather than on the task performance of ministry workers. Although the study of Atanda [24] is related to this study, the dependent variables were different.

\section{Conclusions}

This study was designed to uncover the bivariate and composite ties of strategic planning and staff management to the effectiveness of postgraduate programmes in universities. The quantitative research methodology was adopted to assess the views of administrators on the subject. It is concluded that there is significant partial and composite ties of strategic planning and staff management to the effectiveness of graduate programmes. The practical implications of this finding provide evidence for administrators of postgraduate's programmes to design and manage strategic plans and employees for optimal performance and goal attainment. This finding also contributes to the existing literature in related areas with a piece of new evidence from a developing country's perspective.

\section{Suggestions and Recommendations}

i. There should be a strategy in place for the acquisition and maintenance of facilities needed for the proper functioning of graduate school programs by their coordinator.

ii. Non-governmental organisations, as well as philanthropists, should support the government in the funding of graduate programmes. This will provide ample opportunities that will aid the universities as well as administrators of post-graduate programmes to provide services as expected for the successful implementation of planned policies.

iii. Suitably qualified staff should be adequately recruited and placed into disciplines in the post-graduate programmes based on specialization and competence. Such staff should be adequately motivated (through regular and consistent payment of salaries, promotion, and other incentives), supervised, and evaluated to trigger seriousness.

\section{Limitations and Future Researches}

The small sample of this study constitutes its major weakness. The study is also limited due to its narrow scope on a few universities in a state in Nigeria. It is, therefore, recommended that large-scale future studies on related areas be conducted to validate and supplement this study's findings.

\section{Acknowledgements}

The authors are grateful to all the research assistants who assisted in the data collection and the respondents for providing the raw data used for analysis.

\section{Funding}

No external funding was received for this study.

\section{REFERENCES}

[1] Owan, V. J., Offu, O. E. "Standardised predictive linear models of managerial processes and the sustainability of graduate programmes (SGPs) in universities : A case study." Contemporary Mathematics and Science Education, Vol 2, No. 1, Article ep21006, 2021. https://doi.org/10.30935/con maths/9681

[2] Eze, T. I., Nwakanma, S., Obidile, J. I. "Post-graduate studies completion time in vocational and technical education programmes in South-South Nigerian Universities: Students' related determinants." International Journal of Vocational Education and Training Research, Vol 6, No 2, pp. 34-40, 2020.

[3] Owan, V. J., Bassey, B. A. "Standardised causal statistical equations of curriculum management on the viability of graduate programmes in universities: The Mediation of institutional effectiveness" A Preprint in SocArXiv, 2021. https://doi.org/10.31235/osf.io/9ekmr

[4] Mbon, U. F., Omorobi, G. O., Owan, V. J., Ekpenyong, J. A. "Analysis of the quality of educational resources and effective instructional service delivery in Nigerian Universities." International Journal of Education and Evaluation, Vol 5, No. 7, pp. 25-34, 2019. https://doi.org/10.5281/zenodo.4458688

[5] Omorobi, G. O., Mbon, U. F., Owan, V. J., Ekpenyong, J. A. "Participative management practices and institutional goal attainment in Nigerian universities." American Journal of Social Sciences and Humanities, Vol 5, No. 1, pp. 169-177, 2020. https://doi.org/10.20448/801.51.169.177

[6] Huxley, M. "Administrative coordination, urban management and strategic planning in the 1970s". In The 
Australian Metropolis.” Routledge, pp. 131-148, 2020. https://doi.org/10.4324/9780203362518-9

[7] Ojha, D., Patel, P. C., Sridharan, S. V. "Dynamic strategic planning and firm competitive performance: A conceptualization and an empirical test." International Journal of Production Economics, Vol 222, Article 107509 , 2020. https://doi.org/10.1016/j.ijpe.2019.09.030

[8] Smith, R. D. "Strategic planning for public relations". Routledge, 2020. https://doi.org/10.4324/9781003024071

[9] Arop, F. O., Ekpang, M. A., Nwannunu, B. I., Owan, V. J. "Personnel management and corrupt academic practices in universities in Cross River State, Nigeria." International Journal of Economics, Commerce and Management, Vol 6, No. 9, pp. 405-419, 2018. https://doi.org/10.2139/ssrn.325 0019

[10] [10] Do, Q. H. "Factors affecting job motivation among faculty members: Evidence from Vietnamese public universities." The Journal of Asian Finance, Economics, and Business, Vol. 7, No. 9, pp. 603-611, 2020. https://doi.org/10.13106/jafeb.2020.vol7.no9.603

[11] Khasanah, K. "The effect of lecturer professionalism and teaching motivation on lecturers strengthening the nation's competitiveness (Survey on XYZ college lecturers in central Jakarta city)"." ADI Journal on Recent Innovation, $\begin{array}{lllll}\text { Vol. 2, No. 1, pp. 66-71, } 2020 . & \end{array}$ https://doi.org/10.34306/ajri.v2i1.56

[12] Owan, V. J., Nwannunu, B. I., Madukwe, E. C. "Problems of school management and students, academic performance in secondary schools in Calabar Education Zone, Cross River State, Nigeria." International Journal of Research and Innovation in Social Science (IJRISS), Vol. 2, No. 10, pp. 120-127, 2018.

[13] Bryson, J. M. "Strategic planning for public and non-profit organizations: A guide to strengthening and sustaining organizational achievement." John Wiley \& Sons, 2018.

[14] Wanjala, C. N., Rarieya, J. F. A. "Strategic planning in schools in Kenya: Possibilities and challenges." ISEA, Vol. 42, No. 1, pp. $17-30,2014$.

[15] Abdulkareem, A. Y., Akinnubi, O. P, Oyeniran, S. "Strategic planning and internal efficiency in Nigerian universities." European Science Journal, Vol 8., No. 3, pp. 244-257, 2011.

[16] Nwankwo, I. N., Omebe, C. A., Nwogbo, V. N. "Towards revitalizing the Nigerian university system through strategic thinking and planning." International Journal of Education, Learning and Development, Vol. 4., No. 2, pp. 10-20, 2015

[17] Iso, E. U. "Management of innovations and university system sustainability in South-South Nigeria." (PhD. Thesis), University of Calabar, Nigeria, 2016.

[18] Messah, O. B. "Factors affecting the implementation of strategic plans in government tertiary institutions: A survey of selected technical training institutes." European Journal of Business and Management, Vol. 3, No. 3, pp. 85 - 105, 2014.

[19] Nnaji, E. S. Management of school personnel:
Non-teaching Staff. In C. C. Uchendu \& B. A. Akuegwu (Eds), "Educational Management: A guide for practitioners." University of Calabar Press, pp. 112-127, 2016.

[20] Akeke, M. N. G. Management of school personnel: Academic staff. In C. C. Uchendu \& B. A. Akuegwu (Eds), "Educational management: A guide for practitioners." University of Calabar Press, pp. 89-97, 2016.

[21] Arop, F. O., Owan, V. J., Madukwe, E. C. "Human resource management and teachers' job performance in secondary schools in Akamkpa Local Government Area of Cross River State, Nigeria." International Journal of Social Sciences and Management Research, Vol. 5, No. 2, pp. 2734, 2019. https://goo.gl/TjSrAe

[22] Etor, C. R. "Human resources management and lecturer's job satisfaction in tertiary institutions in Akwa Ibom and Cross River States." Global Journal of Educational Research, Vol. 13, pp. 91-99, 2014.

[23] Akeke, M. N. G., Ofem, W. E. "Human resource management techniques and quality assurance in tertiary institutions in Cross River State." International Journal of Educational Administration Planning and Research, Vol. 8, No. 1, pp. 7-15, 2016

[24] Atanda, A. I. "Influence of personnel management practice on task performance of Oyo State Ministry of Education Staff." International Journal of Educational Administration Planning and Research, Vol. 8, No. 1, pp. 90-104, 2016.

[25] Nyameh, J., Altine, N. J., Yahiya, S. E. "The impact of human resources management on the sustainability of employees' performance." Journal of Emerging Trends in Economics and Management Science, Vol. 5, No. 7, pp. 83-89, 2014.

[26] Ebuara, V. O. "Administration of distance learning in the educational centre and quality assurance implementation in Cross River State." International Journal of Educational Administration Planning and Research, Vol. 7, No. 2, pp. 132-143.

[27] Adeyemi, U. M., Akpakwu, K., Aliyu, S. O. "Human resource management and teachers' job performance in the northwest senatorial district of Benue State, Nigeria." ( $\mathrm{PhD}$ Dissertation), Benue State University, Makurdi, 2015.

[28] Edet, A. O., Benson, U. K., Williams, R. E. "Principals' conflict resolution strategies and teachers' job performance in public secondary schools in Akwa Ibom State, Nigeria." Journal of Educational and Social Research, Vol. 7, No. 2, pp. 113-125, 2018 https://doi.org/10.5901/jesr.2017.v7n2p 153

[29] Imhangbe, O. S., Okecha, R. E., Obozuwa, J. "Principals' leadership styles and teachers' job performance: evidence from Edo State, Nigeria." Educational Management Administration \& Leadership, Vol. 47, No. 6, pp. 909-24, 2019. https://doi.org/10.1177/1741143218764178

[30] Owan, V. J. "Conflict management strategies and secondary school teachers' job effectiveness in Obubra Local Government Area of Cross River State, Nigeria". (B.Ed. Project), University of Calabar, Calabar, Nigeria, 2018. https://doi.org/10.13140/RG.2.2.35015.55200

[31] Arop, F. O., Owan, V. J., Ekpang, M. A. "School hazards 
1970 Strategic Planning and Staff Management as Determinants of Post-Graduate Programmes' Effectiveness in Universities

management and teachers' job effectiveness in secondary schools in Ikom Local Government Area, Cross River State,
Nigeria." International Journal of Education and Evaluation, Vol. 4, No. 9, pp. 38 - 49, 2018.
ii $0000-0002-9950-326 \mathrm{X}$
iii $0000-0002-9080-8104$
iv $0000-0002-9979-399 \mathrm{X}$
v 0000-0001-5715-3428

i 0000-0002-9745-6922 